\title{
Éditorial
}

\section{Les Français et l'orthodontie : 20 ans d'évolution}

L ongtemps associé à l'esthétique (qui reste le principal motif de consultation), le regard des Français sur l'orthodontie a évolué ces 20 dernières années. Une récente étude ${ }^{1}$ commandée par la Fédération Française d'Orthodontie (FFO) révèle que les Français prennent de plus en plus conscience des bienfaits pour la santé d'un traitement orthodontique (voir le schéma ci-contre) et que ceux ayant déjà eu recours à un traitement sont très nombreux à être satisfaits des résultats obtenus.

$39 \%$ des personnes interrogées déclarent avoir déjà porté ou porter aujourd'hui un appareil orthodontique et $16 \%$ estiment qu'ils auraient besoin de ce type de traitement. Ces chiffres portent à $55 \%$ la proportion des Français en situation de besoin de traitement orthodontique.

Si l'esthétique reste la principale motivation pour

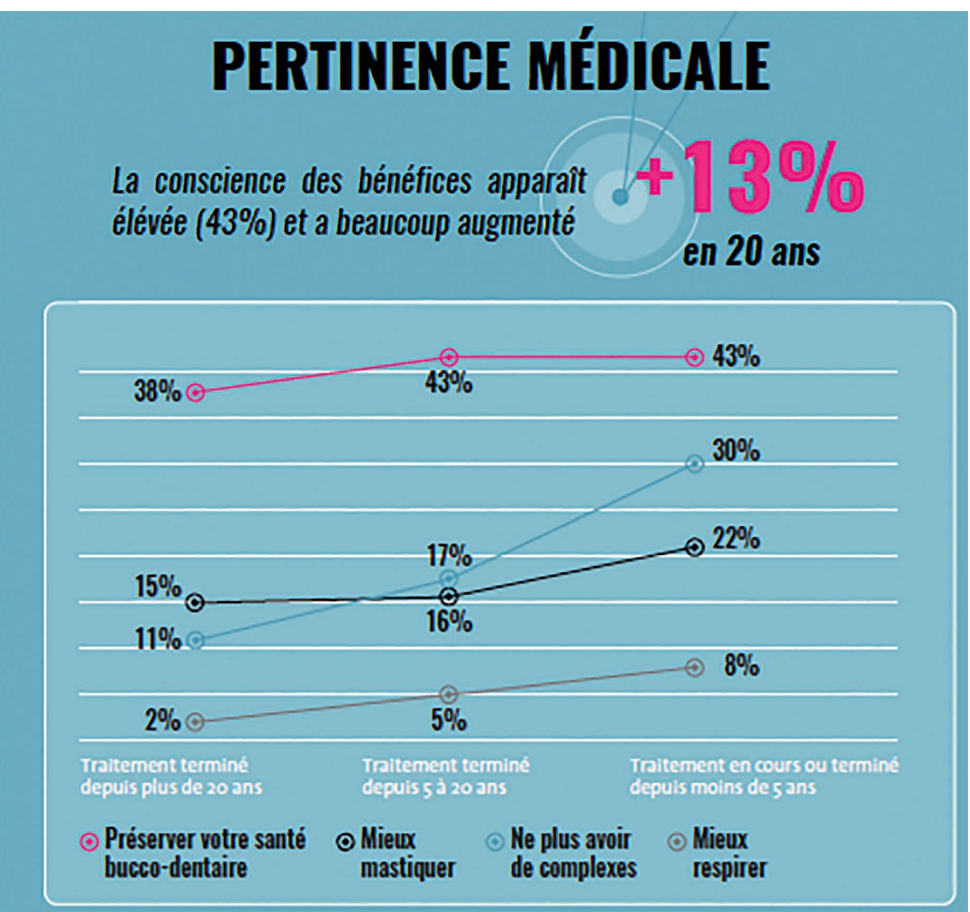

Les valeurs relatives à l'amélioration de la santé confirment la notion de pertinence médicale liée aux traitements d'orthodontie.

entreprendre un traitement d'orthodontie, avec $61 \%$ des répondants qui justifient cette démarche dans l'optique d'avoir un joli sourire, la conscience des bénéfices en matière de santé bucco-dentaire a, en 20 ans, nettement augmentée. En effet, 8 \% des personnes interrogées ont déclaré réaliser un traitement orthodontique dans le but d'améliorer la ventilation.

1. Enquête réalisée par Harris Interactive en ligne du 7 au 12 juillet 2017. Échantillon de 2000 personnes, représentatif des Français âgés de 15 ans à 65 ans. Au sein de cet échantillon, 782 personnes ont déclaré suivre ou avoir suivi un traitement orthodontique. 
Cette étude montre aussi que le dentiste traitant reste le principal initiateur d'un traitement orthodontique, qu'il s'agisse du besoin de traitement ( $48 \%$ des traitements terminés depuis moins de 5 ans versus $39 \%$ des traitements terminés depuis plus de 20 ans) ou du choix de l'orthodontiste (49\% en général et $59 \%$ chez les 35-49 ans).

En dépit des désagréments liés au traitement, qui restent reconnus par une grande partie des patients, le niveau de satisfaction de la manière dont il s'est déroulé et du résultat obtenu s'avère très élevé (respectivement $83 \%$ et $84 \%$ ). II s'élève même à $94 \%$ pour les traitements terminés depuis moins de 5 ans. La satisfaction du traitement est telle qu'une très large majorité de ceux qui ont suivi un traitement orthodontique recommanderaient ce même traitement à un proche (89\%), un taux de recommandation plus important encore parmi les Français traités par appareil invisible (95\%).

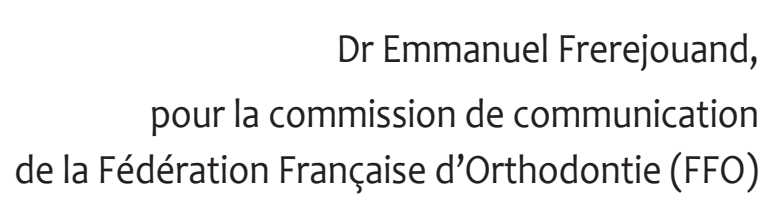

Les opinions émises n'engagent que leurs auteurs. 